\title{
PATENT PLEDGE - Os Compromissos de Patente: análise jurídica e tecnológica
}

\author{
PATENT PLEDGE - Patent Commitments: legal and technological \\ analysis
}

\author{
Silvia Beatriz Beger Uchôa ${ }^{1}$ \\ Bruno Beger Uchôa ${ }^{2}$ \\ ${ }^{1}$ Universidade Federal de Alagoas, Maceió, AL, Brasil \\ ${ }^{2}$ Procuradoria-Geral Federal, Cuiabá, MT, Brasil
}

\begin{abstract}
Resumo
$\mathrm{O}$ aqui denominado Compromisso de Patente, tradução livre do termo Patent Pledge, trata de um instituto relativamente recente, podendo ser definido como uma promessa realizada de forma pública por detentores de patente, os quais permitem a exploração de suas patentes por terceiros, a partir de determinadas condições. $\mathrm{O}$ artigo procura definir essa espécie de ato unilateral e fonte de obrigações, identificando as suas características, diversas formas e a motivação para o seu estabelecimento. São abordados aspectos jurídicos, de forma a relacionar os conceitos com o ordenamento jurídico nacional. Também é realizada uma análise de um compromisso feito por uma empresa, a Tesla Inc., enfatizando os pontos positivos e negativos do ato e se as tecnologias disponibilizadas coadunam com a proposta da empresa e sua motivação para o compromisso de patente. Conclui-se que se pode considerar o compromisso de patente como uma forma de transferência de tecnologia, e que pode incluir diversas maneiras, tanto em relação a acesso às patentes, formas de remuneração e existência ou não de condições especificadas. Apesar do anúncio da Tesla ter surgido como uma notícia extremamente positiva, os beneficiários do uso das patentes devem observar uma série de cuidados em relação às condições especificadas.
\end{abstract}

Palavras-chave: Patentes. Compromisso de Patente. Tesla.

\begin{abstract}
The so-called Patent Pledge is a relatively recent legal institute and can be defined as a publicly held pledge by patent holders to allow the use of their patents by third parties. The article seeks to define this kind of unilateral act, identifying its characteristics, various forms and motivation for its establishment. Legal aspects of Brazilian legislation are approached in order to relate the concepts to national law. An analysis of a commitment made by a company, Tesla, Inc., is also performed, emphasizing its strengths and weaknesses, and if the technologies available are in line with the company's proposal and its motivation for patent commitment. It is concluded that patent pledge can be considered as a form of technology transfer, and that it may include several ways, since related to patent access, forms of remuneration until the existence of specified conditions or not. Although Tesla's announcement came as extremely positive news, patent recipients should observe a number of cautions regarding the specified conditions.
\end{abstract}

Keywords: Patents. Patent Pledge. Tesla.

Área Tecnológica: PI. Desenvolvimento e Políticas Públicas. 


\section{Introdução}

A inovação tecnológica está, indubitavelmente, relacionada ao sucesso das empresas, em maior ou menor intensidade, de acordo com a área de atuação. O Manual de Oslo define inovação tanto como uma atividade inovadora como o resultado dessa atividade:

Uma inovação é um produto ou processo novo ou melhorado (ou a combinação de ambos), que se diferencia significantemente dos produtos ou processos anteriores $e$ que tem sido colocado à disposição de usuários potenciais (produto) ou trazido para uso interno da unidade (processo). (OECD/EUROSTAT, 2018)

O termo unidade se refere nessa definição ao ator que é responsável pela inovação, podendo ser uma empresa, uma entidade governamental ou não governamental, entre outros.

Teruya, Lima e Winter (2015) apontam que o progresso tecnológico está relacionado a três fatores: a cumulatividade do conhecimento, a oportunidade de utilizar o conhecimento acumulado e este trazer retornos extraordinários e a apropriabilidade, através do acesso ao conhecimento científico, tecnologias, fatores de produção, de comercialização, do mercado e do ambiente regulatório. Ou seja, para que o inovador se sinta motivado para desenvolver novos produtos/ processos, há que se ter o retorno do capital investido, e para tal, a proteção da propriedade intelectual tem um papel fundamental, especialmente quando se trata de produtos inovadores, os quais podem ser protegidos por meio de patentes de invenção ou de modelo de utilidade.

O sistema legal de patentes tem um aspecto dualista, que por um lado permite que o detentor da tecnologia possa excluir terceiros de usar o seu produto/processo sem a sua permissão, durante determinado tempo, e obter retorno de seu investimento, e por outro lado expõe a tecnologia, de forma que a sociedade possa se beneficiar do conhecimento contido no documento de patente e, de acordo com linhas de pensamento, alavancar a inovação.

Como bens móveis, segundo o art. $5^{\circ}$ da Lei n. 9.279/1996 (BRASIL, 1996), as patentes garantem ao titular o exercício de certa liberdade sobre a disposição de seu patrimônio imaterial, que, por sua autonomia privada, poderá ceder ou licenciar a sua exploração, inclusive mediante atos unilaterais de vontade, mantendo concomitante a propriedade sobre a patente.

No presente, em um mundo cada vez mais globalizado, as empresas têm buscado diversas formas de cooperação para inovar, seja através de joint ventures, cooperação para pesquisas conjuntas entre empresas e entre estas e instituições de pesquisa públicas e privadas, entre outras, o que pode trazer redução de custos e maior rapidez no processo de inovação.

Em 2014, Elon Musk surpreendeu o mundo ao anunciar que a Tesla: "não iria iniciar processos de patentes contra qualquer um que, de boa-fé, queira usar a sua tecnologia" (HILL, 2016). O título "All our patent are belong to you", estampado na página eletrônica da empresa (TESLA, 2014), trouxe uma série de reações, inicialmente positivas, e posteriormente, cautelosas, sobre esse aspecto.

Considerando-se que a inovação requer investimentos, e que a proteção por patentes pode garantir que outros sejam excluídos de utilizar a tecnologia durante determinado período, garantindo que a empresa possa usufruir do retorno de sua pesquisa e desenvolvimento, qual seria a motivação para que a Tesla tomasse essa iniciativa, e quais aspectos legais devem ser observados? 
Este artigo procura responder a essas questões, inicialmente através de uma breve revisão sobre Compromissos de Patente e suas formas e, em seguida, avaliando quais são as tecnologias disponibilizadas pela Tesla, comparando-as com o total de tecnologias patenteadas pela empresa, a partir dos dados da lista de patentes contra as quais não se teria processo por uso de boa-fé, conforme colocado pelo fundador da empresa (TESLA, 2014). Esse anúncio levou a uma segunda empresa, a Toyota, também permitir o uso, livre de royalties, de cerca de 5.700 patentes relacionadas a células combustível de hidrogênio (CONTRERAS, 2018).

Não se pretende discutir os motivos que levaram a empresa Tesla a realizar essa abertura para a utilização de seus ativos intangíveis em forma de patentes, apenas será exposto o que foi publicado pela própria empresa e estudiosos do assunto, e também por alguns críticos da atitude tomada, os quais procuram observar além do exposto por Musk.

\section{Metodologia}

O presente artigo trata de uma pesquisa bibliográfica exploratória qualitativa em referências bibliográficas e on-line e quantitativa em bases de patentes.

Inicia-se com uma revisão do assunto "compromisso de patentes", sendo feita uma busca em bases de artigos e livros sobre o assunto, utilizando-se o termo "patente pledge" com as aspas delimitando o termo exato. Após a busca em base de artigos e livros, encontrou-se na base Scopus 29 publicações, sendo 19 referentes a capítulos de um livro organizado pelo autor Contreras (2018). Também foram utilizados os sítios eletrônicos de empresas que praticam esses compromissos de patentes. Foram buscadas referências para análise jurídica na legislação nacional, procurando relacionar as definições encontradas nos estudos realizados ao possível tratamento em território brasileiro.

Em relação às patentes, foi utilizada a plataforma Orbit ${ }^{\circledR}$ para a análise das famílias de patentes (doravante denominadas apenas "patentes") da empresa Tesla, sendo esse termo inserido no campo depositante e delimitado o período de 1999 a 2018, perfazendo 20 anos, período em que se tem a vigência de uma patente de invenção, considerando-se em todos os casos a data de depósito. Após o levantamento das patentes da empresa nesse período, fez-se a comparação com a listagem das patentes constantes na página eletrônica do compromisso declarado da Tesla, visando a comparar as tecnologias disponibilizadas com as demais recuperadas na busca, usando-se a Classificação Internacional de Patentes. Foram realizadas outras análises, como a dos anos de prioridade e a dos países citados nas patentes do compromisso. Para a comparação dos dados foram utilizadas planilhas eletrônicas Excel $\AA$.

\section{Compromissos de Patente e o seu Tratamento Jurídico}

Neste item procura-se abordar aspectos sobre os compromissos de patente, o que são, quais as suas características e formas, e como estão sendo realizados e estudados.

O assunto trata, como já exposto, de um paradigma, trazido pela globalização e pela cada vez mais intensa interação entre empresas e indivíduos. Em termos jurídicos, há que se avaliar a legislação de cada país envolvido, pois o sistema de patentes, além de temporal, também é territorial. 
Trata-se de termo relativamente novo, pouco estudado, podendo ser colocada a data de 2012 como o início da observação do comportamento de empresas, ao serem colocados compromissos de uso de suas patentes pelas empresas Google e Apple, segundo Contreras (2018a). O referido autor iniciou nesse ano a coleta de compromissos de patentes, reunindo mais de 150 diferentes acordos, envolvendo milhares de patentes, e iniciando o interesse de estudos acadêmicos, especialmente os relacionados ao arcabouço legal (CONTRERAS, 2018). Ehrneperger e Tietze (2019) mencionam a mesma data para o início dos estudos, mas citam ainda que, desde a década de 1940, já havia organizações que praticavam atos que envolviam um valor razoável de royalties e uma ampla disponibilidade das suas patentes.

Ziegler, Gassmann e Frieske (2014) estudaram 26 casos de "liberação" de patentes, denominação dada pelos autores, identificando casos desde 1970.

Hill (2016) cita que o tipo de patente concedida mudou drasticamente com o tempo, pois as primeiras patentes descreviam invenções completas em um ou dois documentos, e atualmente a complexidade dessas tecnologias pode envolver centenas de patentes de inúmeros diferentes indivíduos e organizações. Essa complexidade em indústrias de alta tecnologia leva à necessidade da citada cumulatividade de inovação, na qual uma nova invenção pode estar baseada em uma série de invenções anteriores (HILL, 2016).

Essa dependência de invenções anteriores pode levar a uma série de questionamentos, pois pode criar monopólios, e ao mesmo tempo, refrear o processo de inovação. Contreras (2018) cita que os Compromissos de Patente (Patent Pledge) seriam o grau intermediário entre a exploração dos direitos exclusivos de patentes e a cessão da patente para acesso livre ao público. Ou seja, as empresas ainda detêm a propriedade das patentes, podendo exercer alguns direitos sobre elas.

Ehrneperger e Tietze (2019) definem o termo como "uma intervenção anunciada publicamente por entidades proprietárias de patentes ('promotores') para licenciar patentes ativas para um público restrito ou irrestrito, de forma livre ou vinculada a determinadas condições, por uma compensação monetária razoável ou inexistente". Como se expõe a seguir, há diversas formas de oferecer os ativos em questão para esse licenciamento, podendo também serem direcionados a um determinado grupo de empresas ou abertos para todos os que tiverem interesse em utilizá-los, havendo ou não condições para a sua utilização.

Como já mencionado, a inovação ocorre de formas diferentes, de acordo com o setor da economia considerado, e assim também pode se separar os diversos setores e seus respectivos compromissos de patente. Contreras (2018) cita quatro grandes setores como os representantes de empresas que realizam os compromissos de patente: Tecnologia da Informação e Comunicação (TIC), Programas de Computador de Código Aberto, Tecnologia Limpa/Verde e Ciências da Vida.

A caracterização dos compromissos de patentes pode envolver centenas e até milhares de patentes, podendo ser feita de forma específica, com a identificação de cada patente envolvida, por exemplo pelo seu número, ou através da descrição da categoria a qual ela pertence. Nesse último caso, a descrição deve permitir a adequada identificação dos documentos do compromisso (CONTRERAS, 2018).

Segundo Contreras (2018), o crucial para o compromisso é o comprometimento do detentor do direito de patente em relação a esse compromisso a ser celebrado. $\mathrm{O}$ autor cita três categorias, descritas a seguir: 
(1) o compromisso principal de licenciar patentes, seja em termos livres de royalties ou em FRAND, ou para não declarar direitos de patentes (compromissos de acesso primário); (2) compromissos mais detalhados relativos às taxas de royalties ou outros valores que serão cobrados (compromissos de royalties secundários) e (3) compromissos de não-royalties. (CONTRERAS, 2018, Tradução nossa)

O termo FRAND se refere a uma forma de compromisso que pressupõe um licenciamento justo da tecnologia entre membros de uma organização ou mesmo de fora dessa entidade. Algumas tecnologias necessitam de normas ou padronizações para que funcionem adequadamente em conjunto, como celulares e computadores que utilizam redes sem fio. Para que isso ocorra, há organizações de desenvolvimento de padronização (SDO) que procuram fazer com que patentes envolvidas nessas tecnologias e essenciais para seu funcionamento possam ser licenciadas no modo FRAND, de "Fair, Reasonable and Non-Discriminatory", para todos os membros da organização de padronização e mesmo para não membros (LEWIS, 2014). Sem esse tipo de compromisso, os detentores das principais tecnologias envolvidas no produto/processo teriam uma vantagem gigantesca sobre os demais. Esse trata do compromisso de acesso primário.

O compromisso de royalties secundários nasce da incerteza do que seria um acordo justo (FRAND) em termos de taxas de cobrança de royalties, estabelecendo taxas mínimas ou a forma de cálculo dessas taxas, sendo essa última comum no setor de comunicação sem fio (CONTRERAS, 2018).

A terceira categoria diz respeito a compromissos que envolvem o não pagamento de royalties pelo uso das patentes, fazendo com que o detentor das mesmas procure obter lucros de forma diversa ao licenciamento desses ativos. Envolve um tratado de não injunção, quando ocorre uma quebra de um compromisso FRAND por uma das partes utilizar tecnologia padronizada dependente dessas patentes, ou ainda, uma Licença Defensiva de Patentes, a qual previne a venda ou a transferência da tecnologia por empresas que não realizaram o compromisso de patentes (CONTRERAS, 2018).

Essa divisão em categorias é recente, e pode ocorrer em mais de um compromisso realizado, ou seja, o compromisso secundário pode ser inserido em um acordo de compromisso primário, de forma a evitar o cometimento de abusos, bem como os compromissos de não royalties, para evitar transferências da tecnologia de forma indevida.

Em relação à forma dos compromissos, Contreras (2018) cita que podem ser compromissos coordenados, como os realizados entre membros de um grupo como uma organização de desenvolvimento de normas (SDO), apresentando características semelhantes, mas sem serem, necessariamente, iguais; e os unilaterais, nos quais os detentores dos direitos de patente apresentam o compromisso de forma independente e voluntária.

Já Ziegler, Gassmann e Frieske (2014) categorizaram os CP em quatro grupos: a realização de lucros pela melhoria de seus produtos pelos usuários e pelo efeito de rede, comum na indústria de software; a doação de patentes consideradas obsoletas para universidades e outras instituições de pesquisa, com a finalidade de diminuição de custos de manutenção; o efeito de catalisador de inovação, no qual a empresa catalisadora da inovação libera o uso de patentes não essenciais para universidades ou outras instituições de pesquisa para desencadear atividades de inovação e abrir novos campos de negócios; e no quarto tipo, a empresa fornecedora 
de tecnologia disponibiliza gratuitamente patentes essenciais específicas para terceiros, o mais próximo do Patent Pledge, discutido neste artigo.

Ehrneperger e Tietze (2019) criaram uma taxonomia de licenciamento de patentes que compreende oito diferentes categorias, baseada em três dimensões: a acessibilidade, na qual os detentores podem permitir o acesso restrito ou aberto, com diversas variações, a compensação, ou seja, quanto a empresa obtém de retorno por seus ativos, variando de alto preço até livre de royalties, e as condições, variando de nenhuma condição à indireta e direta. Nesse caso, os autores criaram uma taxonomia de todos os processos de licenciamento, não restritos aos compromissos de patente.

Algumas empresas incorporaram o compromisso de patentes em seus websites, como a Tesla, que posta em sua página eletrônica o acordo de modo menos formal (TESLA, 2014) e a Microsoft, citada por Contreras (2018), mas com dificuldade de encontrar em sua página, pois em 2015 houve a migração dos dados dessas patentes da empresa para outra página eletrônica, porém sem esclarecer um compromisso de patentes. A ORoPO, sigla da Fundação Open Register of Patent Ownership, se define como uma base de dados global de detentores de patentes validados por companhias comprometidas com o acesso aberto e com a transparência (OROPO, 201?). Já a Google mantém em sua página eletrônica uma listagem das patentes (GOOGLE, 201?). Outras formas de publicização do compromisso seriam uma declaração oficial para o estado e a menos formal, como um artigo publicado (CONTRERAS, 2018). Ehrneperger e Tietze (2019) listaram e analisaram 60 compromissos de patente, envolvendo 80 organizações, concluindo que há forte conexão entre os $\mathrm{CP}$, inovação aberta e programas de computador de código aberto.

Em termos legais, deve-se atentar para o fato de existirem as diversas formas de compromisso, e que uma publicação em uma página eletrônica da empresa seria suficiente para o uso da propriedade industrial por terceiros. Deve-se atentar para a forma como foi colocado esse compromisso, o que será discutido adiante, em relação à própria empresa Tesla, como por exemplo, o que significa o uso de boa-fé.

Não há dúvida de que, no Brasil, os direitos de propriedade industrial são considerados bens móveis para efeitos legais, nos termos do artigo $5^{\circ}$ da Lei n. 9.279/1996, e, portanto, o titular da patente exerce certa liberdade sobre a disposição de seu patrimônio imaterial.

A própria Lei de Propriedade Industrial regulamenta a cessão e o licenciamento da exploração da patente. De acordo com os artigos 58 a 60 da Lei n. 9.279/1996, a patente poderá ser cedida, cabendo ao Instituto Nacional da Propriedade Industrial - INPI fazer as anotações da cessão e, somente a partir da sua publicação pelo INPI passará a produzir efeitos perante terceiros.

No caso do licenciamento voluntário para a exploração das patentes, seu regramento se encontra nos artigos 61 a 67 da Lei n. 9.279/1996 (BRASIL, 1996):

\section{CAPÍTULO VIII DAS LICENÇAS}

Seção I

Da Licença Voluntária

Art. 61. O titular de patente ou o depositante poderá celebrar contrato de licença para exploração. 
Parágrafo único. O licenciado poderá ser investido pelo titular de todos os poderes para agir em defesa da patente.

Art. 62. O contrato de licença deverá ser averbado no INPI para que produza efeitos em relação a terceiros.

$\S 1^{\circ} \mathrm{A}$ averbação produzirá efeitos em relação a terceiros a partir da data de sua publicação.

$\S 2^{\circ}$ Para efeito de validade de prova de uso, o contrato de licença não precisará estar averbado no INPI.

Art. 63. O aperfeiçoamento introduzido em patente licenciada pertence a quem o fizer, sendo assegurado à outra parte contratante o direito de preferência para seu licenciamento.

Seção II

Da Oferta de Licença

Art. 64. O titular da patente poderá solicitar ao INPI que a coloque em oferta para fins de exploração.

$\S 1^{\circ}$ O INPI promoverá a publicação da oferta.

$\S 2^{\circ}$ Nenhum contrato de licença voluntária de caráter exclusivo será averbado no INPI sem que o titular tenha desistido da oferta.

$\S 3^{\circ} \mathrm{A}$ patente sob licença voluntária, com caráter de exclusividade, não poderá ser objeto de oferta.

$\S 4^{\circ} \mathrm{O}$ titular poderá, a qualquer momento, antes da expressa aceitação de seus termos pelo interessado, desistir da oferta, não se aplicando o disposto no art. 66.

Art. 65. Na falta de acordo entre o titular e o licenciado, as partes poderão requerer ao INPI o arbitramento da remuneração.

$\S 1^{\circ}$ Para efeito deste artigo, o INPI observará o disposto no $\S 4^{\circ}$ do art. 73.

$\S 2^{\circ}$ A remuneração poderá ser revista decorrido 1 (um) ano de sua fixação.

Art. 66. A patente em oferta terá sua anuidade reduzida à metade no período compreendido entre o oferecimento e a concessão da primeira licença, a qualquer título.

Art. 67. O titular da patente poderá requerer o cancelamento da licença se o licenciado não der início à exploração efetiva dentro de 1 (um) ano da concessão, interromper a exploração por prazo superior a 1 (um) ano, ou, ainda, se não forem obedecidas as condições para a exploração.

O Compromisso de Patente (Patent Pledge), em especial o realizado pela Tesla e objeto deste artigo, se aproxima do licenciamento de exploração, mas com ele não se confunde. Apesar de ambos permitirem a exploração da patente por terceiros, o Compromisso de Patente ostenta natureza jurídica de ato unilateral, e as obrigações dele decorrentes nascem da simples declaração do detentor da patente, formando-se no instante em que o agente se manifesta com a intenção de assumir o dever obrigacional, no caso, o dever de permitir a exploração da patente e não buscar questionar possíveis infrações.

Enquanto o licenciamento da exploração da patente por contrato possui regramento na Lei n. 9.279/1996, não há no ordenamento jurídico brasileiro a previsão do Compromisso de Patente, que deve, portanto, receber o tratamento dado ao direito de propriedade do bem móvel, podendo seu proprietário dispor (art. 1.228 do Código Civil), ainda que estabeleça certos requisitos, em conformidade com a livre iniciativa, um dos fundamentos da República Federativa do Brasil (artigo $1^{\circ}$, IV, da Constituição da República) (BRASIL, 1988). 
Sob uma visão jurídica, a aplicação de um Compromisso de Patente (Patent Pledge) no Brasil, na forma realizada pela Tesla, deve ser encarada com certa precaução em relação à sua aplicabilidade e executoriedade. Apesar de estar dentro da autonomia privada, como poder do indivíduo de criar, nos limites da lei, normas jurídicas de seu próprio comportamento, sua limitação e fragilidade residem justamente na ausência de previsão normativa específica.

Portanto, pode-se conceituar o Compromisso de Patentes (Patent Pledge) como um ato unilateral de vontade em que o titular da patente se compromete a permitir que terceiros explorem a patente mediante certos requisitos ou não, podendo criar obrigações plenamente exigíveis desde a sua declaração pelo titular.

Para a compreensão do porquê uma empresa estabelece um compromisso de patentes, deve-se investigar a motivação que a levou a celebrar tal ato. Contreras (2018) cita que o entendimento da taxonomia da motivação pode ser útil para o entendimento dos efeitos legais dos diferentes compromissos, e que mais de uma motivação pode ser considerada em um acordo.

A primeira motivação é a de levar (induzir) outros participantes do mesmo mercado a realizarem alguma coisa, sendo dividida em três segmentos:

Aquela destinada a induzir outras empresas a adotar e fazer investimentos em produtos que cumpram um ou mais padrões de interoperabilidade, aqueles que induzem outras firmas a adotar uma plataforma tecnológica específica favorecida, senão vendido pelo detentor, e aqueles destinados a induzir os participantes do mercado a adotar uma tecnologia de plataforma ampla. (CONTRERAS, 2018, Tradução nossa).

Nesse caso, o detentor das patentes visa a se beneficiar do comportamento de outras empresas, muito mais do que do próprio licenciamento de suas patentes, tanto em um grupo como as SDO, como fora deles. Pode-se citar o caso das tecnologias USB, Wi-fi, 3G/4G, entre outras, nas quais houve um efeito de rede, ampliando a compatibilidade de equipamentos e assim induzindo maior consumo e retorno dos investimentos nas tecnologias associadas (CONTRERAS, 2018). Essa motivação trata ainda de fazer parte de uma rede, como descrita anteriormente, de um "ecossistema de produtos interoperáveis". Como muitas vezes a tecnologia é propriedade de mais de uma empresa, ou uma empresa detém a tecnologia, mas se interessa que outras desenvolvam produtos compatíveis, essa motivação pode ser considerada complementar à primeira.

O desenvolvimento de mercado está dentro da indução, e diferentemente das duas primeiras, pode ser direcionada a uma grande tecnologia muito mais do que a um produto ou a uma padronização (CONTRERAS, 2018). Trata-se nesse caso da Tesla, envolvendo a tecnologia de carros elétricos, de acordo com a fala de Musk: "A Tesla foi criada para acelerar o advento do transporte sustentável, e essa política pretende incentivar o avanço de uma plataforma comum e de rápida evolução para veículos elétricos, beneficiando a Tesla, outras empresas que produzem veículos elétricos e o mundo" (TESLA, 2014). Percebe-se, apesar das críticas de alguns autores, que o objetivo do compromisso seria a evolução de um meio de transporte elétrico e que a abertura das patentes traria parceiros a desenvolverem produtos correlatos, pois além dos veículos existe toda uma mudança de comportamento em relação ao seu uso, desde locais para abastecimento até peças e os automóveis propriamente ditos.

A segunda motivação trata da possibilidade de uma ação coletiva, considerada mais consistente e menos custosa, podendo ser exemplificada pela "Eco Patent Commons", a qual 
cita ter sido criada para: "facilitar o uso da inovação existente que protege o meio ambiente, e incentivar a colaboração para novas inovações através de uma coleção online de patentes ambientalmente benéficas prometidas pelas empresas-membro para uso livre por qualquer pessoa" (CORPORATE ECO FORUM, 2015).

A restrição voluntária trata, como o nome diz, de uma ação voluntária de um detentor de patentes no sentido de não tomar determinadas ações contra infrações de certos indivíduos ou empresas. Normalmente esse compromisso é direcionado a órgãos governamentais, visando à diminuição de riscos de acusação de uso das patentes para a formação de trustes e assim evitar riscos. Exemplo de compromisso desse tipo é o FRAND.

Ziegler, Gassmann e Frieske (2014) citam que a motivação para a liberação de patentes pelas empresas reside na quarta categoria, compondo uma combinação de boa vontade, de servir à sociedade e de dar acesso a terceiros criando um pool de patentes. No sentido de servir à sociedade, argumenta que a patente, na condição de liberada para uso, garante que a tecnologia esteja aberta para todos.

Qualquer que seja a motivação para o estabelecimento de compromissos de patente, no Brasil não há notícias de compromisso específico com esses fins, no entanto, empresas multinacionais atuantes no país, como a Microsoft, se referem a essa possibilidade em seus websites.

\section{Compromisso de Patentes da Tesla}

Como já citado, o compromisso estipula: "A Tesla promete irrevogavelmente que não iniciará uma ação judicial contra qualquer parte por infringir uma Patente da Tesla através de atividades relacionadas a veículos elétricos ou equipamentos relacionados, enquanto essa parte estiver agindo de boa-fé" (TESLA, 2014, tradução nossa).

Ao se acessar a página da empresa, tem-se que age de boa-fé quem não:

- reivindicou, ou ajudou outros a reivindicar ou ter participação financeira em qualquer reivindicação de qualquer patente ou outro direito de propriedade intelectual contra a Tesla ou qualquer direito de patente contra um terceiro pelo uso de tecnologias relacionadas a veículos elétricos ou equipamentos relacionados;

- questionou, ajudou outros a contestar ou teve participação financeira em qualquer questionamento a qualquer patente da Tesla; ou

- comercializou ou vendeu qualquer produto knock-off (por exemplo, um produto criado imitando ou copiando o desenho ou a aparência de um produto da Tesla ou que sugere uma associação ou endosso da Tesla) ou forneceu qualquer assistência material a outra parte fazendo isso (TESLA, 2014, tradução nossa).

Hill (2016) enumera as motivações de Musk para o compromisso de patentes da Tesla, iniciando pelo estabelecimento do mercado, considerando que as vendas de carros elétricos triplicaram nos Estados Unidos desde 2013, mas ainda correspondem a menos de 1/3 das vendas no mercado americano. Continua com outra motivação, que seria a necessidade de haver estações de carga para os carros, considerando que seus carros são $100 \%$ movidos à eletricidade e não híbridos, e que isso contribuiria para a redução de emissão de carbono na atmosfera. Ou seja, uma reinvindicação legítima para suprir uma necessidade de seus usuários. Outra motivação é 
a venda de baterias, especialmente desenvolvidas pela Tesla e que seriam superiores às demais existentes. $\mathrm{O}$ autor fecha afirmando a importância da acumulação da inovação, o que levaria o mercado a um maior desenvolvimento tecnológico. As críticas ao compromisso são oriundas principalmente da forma como está posto na página da empresa, de forma não clara e também que podem ser retiradas a qualquer momento (HILL, 2016).

Morris (2018) cita que a questão de uma empresa usar as patentes da Tesla impede que ela tenha qualquer litígio, mesmo que esse envolva propriedades intelectuais suas, como programas de computador ou até mesmo marcas, desenhos industriais e outros direitos de autor. Exemplifica que se a Tesla copiar um código fonte da referida empresa, essa não poderá contestá-la, abrindo mão de sua propriedade intelectual. Continua ainda citando a impossibilidade de reivindicar direitos contra terceiros relativos à tecnologia de "veículos elétricos ou equipamentos relacionados", inclusive sobre um questionamento de patente da própria Tesla. Em terceira observação, tem-se a indefinição de quais produtos seriam considerados como "produto knock-off", o que poderia levar à infração por copiar um design da Tesla. Ou seja, apesar de parecer uma grande oportunidade, o uso das patentes do compromisso deve ser feito observando-se cuidadosamente, e em termos legais, os aspecto colocados. Hill (2016) cita esses mesmos aspectos em suas críticas.

Em resumo, apesar do anúncio bombástico da Tesla, o compromisso deve ser muito bem avaliado pelas empresas, para que não possa ocorrer um litígio envolvendo propriedade intelectual da outra parte envolvida, considerando-se que essa abre mão de qualquer reivindicação.

\section{Tecnologias Envolvidas no Compromisso de Patentes da Tesla}

Nesta seção é realizada a análise das tecnologias protegidas pela Tesla listadas no compromisso de patentes.

A listagem das patentes do compromisso envolve 361 documentos, publicada na página eletrônica da Tesla. No entanto, como a crítica realizada por Morris (2018) sobre a imprecisão dos termos do compromisso publicado, sobre a listagem também podem ser feitas algumas observações. A primeira diz respeito à forma como algumas patentes são apresentadas, com muitas sendo repetidas, ou seja, da mesma família de patentes, mas não cobrindo todas as patentes da família, e algumas com o título modificado, ou ainda com o título do depósito, tendo havido modificações na concessão da patente. Também não está claro se outros documentos da mesma família, mas que não estejam listados na página eletrônica, também fariam parte do compromisso, pois há de se assim supor, já que se afirma que todas as patentes propriedades da Tesla agora ou no futuro seriam objeto do compromisso. Dos 361 documentos listados, conseguiu-se identificar 138 famílias de patente.

Para fins de primeira análise, na Figura 1 são apresentados os números de documentos de acordo com o escritório de depósito, destacando-se o escritório americano (USPTO) com 249 documentos. Há que se considerar que também são colocados países europeus (FR, DE e GB) e também o escritório europeu de patentes (EP), levando a intuir-se que são 361 documentos, mas podem ser muitos mais, se forem considerados todos os documentos das famílias de patentes. Verifica-se em alguns casos que há os diversos documentos que compõem uma família de patentes, mas nem sempre completas, porém a análise se ateve ao material publicizado pela 
empresa. Se o compromisso é levado tão a sério, questiona-se por que a empresa não atualiza a página com as demais patentes ou não utiliza uma linguagem incorporando o conceito de família de patentes.

Figura 1 - Escritórios de depósito das patentes listadas no acordo de patentes da Tesla

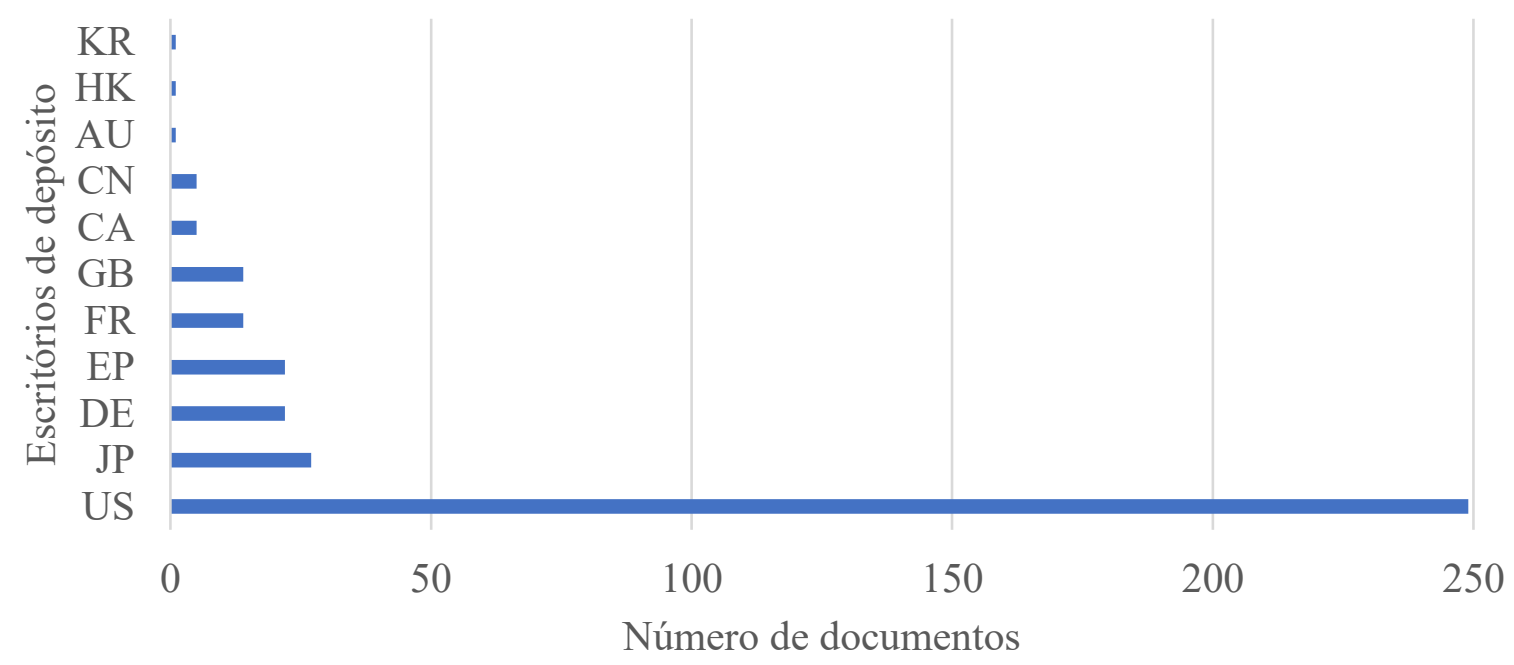

Fonte: Elaborada pelos autores deste artigo (2019)

A partir desses resultados, foi feita a identificação das principais classificações internacionais de patente (CIP) das famílias de patentes listadas pela empresa, apresentadas na Figura 2, com a finalidade de obter informações sobre as áreas tecnológicas envolvidas no compromisso. Foram consideradas as 138 famílias de patentes, mas seis delas não apresentavam CIP, apenas a CPC (classificação cooperativa de patentes) e a classificação do escritório dos Estados Unidos da América. Essas classificações envolviam carregadores de baterias elétricas, conectores elétricos e partes de veículos.

Figura 2 - Classificação Internacional de patentes identificadas na listagem de patentes do compromisso

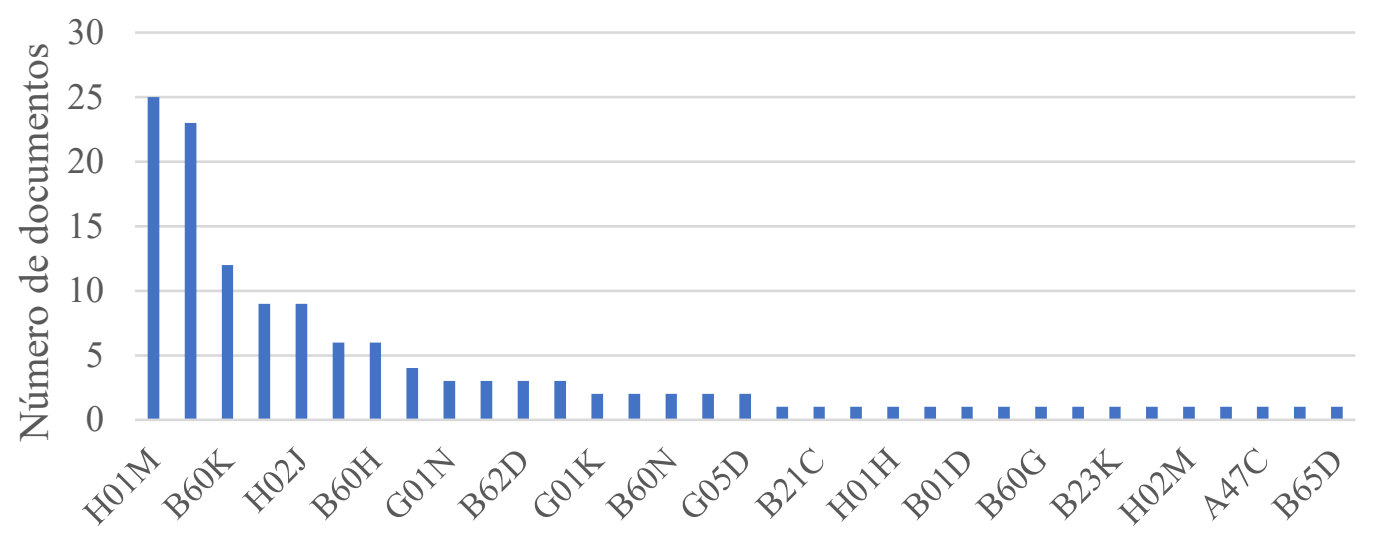

Classificação Internacional de Patentes (CIP)

Fonte: Elaborada pelos autores deste artigo (2019) 
Observando-se as duas CIP de maior ocorrência, tem-se: H01M - Elementos elétricos básicos: processos ou meios, p. ex. baterias, para a conversão direta da energia química em energia elétrica; e B60L - Veículos em geral: propulsão de veículos de propulsão elétrica; suprimento de energia elétrica para equipamentos auxiliares dos veículos de propulsão elétrica; sistemas de freios eletrodinâmicos para veículos, em geral; suspensão magnética ou levitação para veículos; monitoração de variáveis operacionais de veículos de propulsão elétrica; dispositivos de segurança elétrica de veículos de propulsão elétrica. Essas tecnologias estão coadunadas aos objetivos do compromisso de patentes da Tesla, a qual afirma que "essa política pretende incentivar o avanço de uma plataforma comum e de rápida evolução para veículos elétricos" (TESLA, 2014).

As patentes listadas apresentam data de prioridade variando entre os anos de 2005 e 2016, com destaque para os anos de 2009 e 2011, com maior número de documentos (Figura 3).

Figura 3 - Anos da primeira prioridade das patentes listadas no compromisso da Tesla

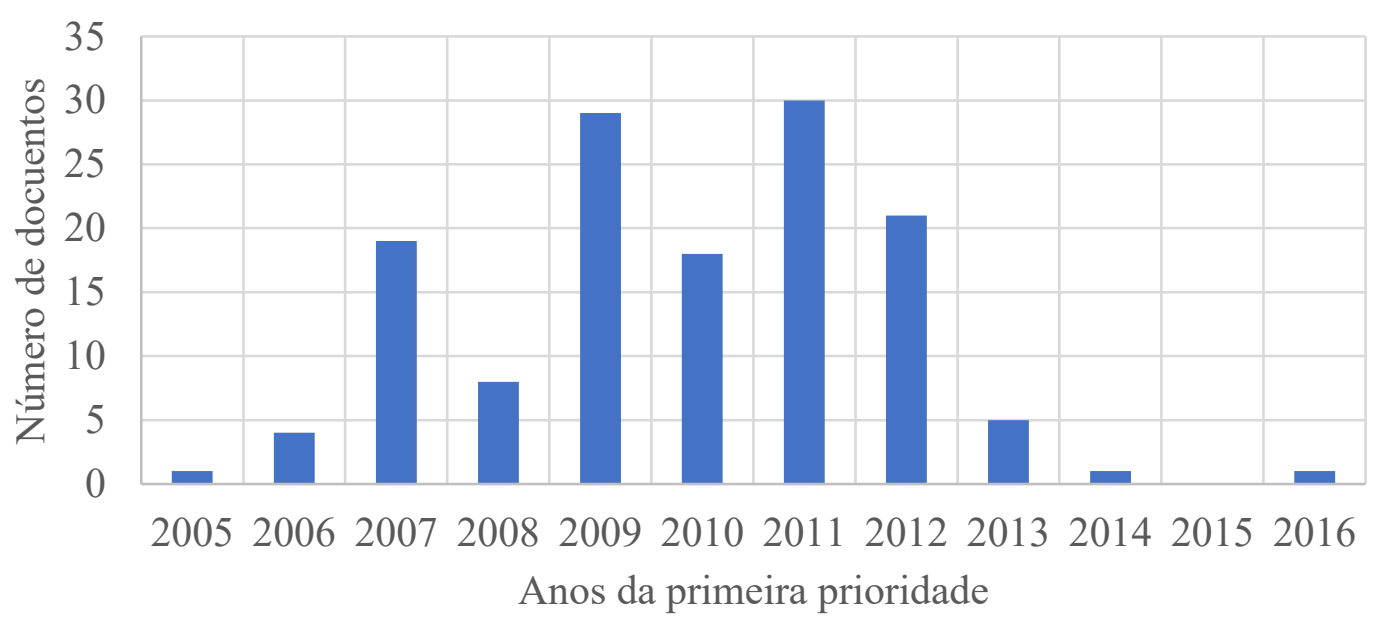

Fonte: Elaborada pelos autores deste artigo (2019)

Foram retornados 808 resultados na plataforma Orbit $\AA$, com o termo Tesla apenas. Com o refinamento para Tesla Motors e outras subsidiárias da empresa, o resultado ficou em 386 famílias de patentes, desde janeiro de 1999. Esses resultados foram utilizados para confrontar e identificar as famílias de patentes da listagem da Tesla. Ao se comparar com os 361 documentos apresentados na página da companhia, já se pode concluir que essa não se encontra atualizada, havendo um número de patentes superior ao listado.

Pode-se observar que em anos mais recentes não houve novas patentes adicionadas à lista da página eletrônica da empresa, o que denota mais uma vez a vagueza do acordo publicado. O declínio a partir do ano de 2013 deve ser investigado, para avaliar se há falta de informações sobre o compromisso.

Pode-se considerar que, apesar de haver a concordância entre o maior número de tecnologias disponibilizadas, verificada a partir das CIP das patentes listadas e a motivação apresentada pela empresa, a alegação de que "todas as nossas patentes são suas" deve ser considerada de forma cuidadosa. Isso por que, ao se avaliar as CIP, há outras tecnologias diferentes das colocadas no anúncio do compromisso de patentes. 


\section{Considerações Finais}

O compromisso de patentes é uma forma que as empresas possuem para que possam aumentar o desenvolvimento de setores específicos da economia, facilitar o acesso a produtos e tecnologias padronizados e também se proteger de acusações antitruste, permitindo que terceiros utilizem a sua propriedade intelectual dentro de certos requisitos estabelecidos. Trata-se de um ato unilateral, com pouca formalidade e, na maioria das vezes, sem se conhecer os beneficiários.

No Brasil, não há regramento jurídico sobre esse assunto, devendo esses compromissos serem avaliados à luz da legislação pertinente sobre propriedade intelectual e propriedade privada. Cada caso deve ser visto de acordo com as peculiaridades do setor e da empresa envolvida.

Patent Pledge, indubitavelmente, como exposto pelos autores estudados, pode ser considerada uma forma de transferência de tecnologia, trazendo diversas variações, tanto quanto à motivação quanto à forma como as patentes são disponibilizadas pelas empresas detentoras dos ativos.

Em relação ao compromisso estabelecido pela Tesla, pode-se afirmar que traz uma série de dúvidas, tanto ao que é considerado boa-fé como às informações colocadas no sítio eletrônico, como, por exemplo, a listagem de patentes. $\mathrm{O}$ beneficiário deve estar atento a todas as nuances contidas nos termos do texto do documento, para não incorrer em infrações ou mesmo ficar impossibilitado de questionar alguma infração cometida pela própria Tesla.

Quanto às tecnologias disponibilizadas, a grande maioria diz respeito a novas baterias, sendo realmente condizente com a chamada motivação para celebrar o compromisso, que é o de desenvolver a área de transporte por veículos elétricos.

Finalizando, pode-se afirmar que os compromissos de patente, sejam eles de que forma venham a ser estabelecidos, vêm trazer para a área de propriedade intelectual mais uma possibilidade de transferência de tecnologia, e que, bem utilizados, trazem benefícios a toda a sociedade. Há que se adaptar o sistema jurídico e disseminar essa possibilidade para as empresas usufruírem dos benefícios do sistema de patentes.

\section{Referências}

BRASIL. Constituição (1988). Constituição da República Federativa do Brasil. Promulgada em 5 de outubro de 1988. [1988]. Disponível em: http://www.planalto.gov.br/ccivil_03/Constituicao/ Constituicao.htm. Acesso em: 2 set. 2019.

BRASIL. Lei n. 9.279, de 14 de maio de 1996. Regula direitos e obrigações relativos à propriedade industrial. Disponível em: http://www.planalto.gov.br/ccivil_03/leis/19279.htm. Acesso em: 26 jul. 2019.

CONTRERAS, J. L. A patent pledge taxonomy. In: CONTRERAS, J. L.; JACOB, M. Patent pledges: Global perspectives on Patent's Law Private Ordering frontier. Northampton: Edward Elgar, 2018. p. 7-36.

CONTRERAS, J. L. The evolving Patent Pledge Landscape. CIGI Papers, [S.l.], n. 166. 2018a. 24 p.

CORPORATE ECO FORUM. CEF Spotlight: Welcome to the Eco-Patent Commons. Disponível em: http://www.corporateecoforum.com/welcome-to-the-eco-patent-commons/. Acesso em: 2 out. 2019. 
EHRNSPERGER, J. F; TIETZE, F. Patent Pledges, open IP, or patent pools? Developing taxonomies in the thicket of terminologies. PLoS ONE. [S.l.], v. 14, n. 8, 2019. Disponível em: web-b-ebscohost. ez9.periodicos.capes.gov.br/ehost/pdfviewer/pdfviewer?vid=1\&sid=501ddedd-5b7c-46e5-80ffa4d187c9c78b\%40pdc-v-sessmgr02. Acesso em: 30 out. 2019.

GOOGLE. Open Patent Non-Assertion Pledge. Disponível em: https:/www.google.com/patents/ opnpledge/patents/. [201?]. Acesso em: 10 ago. 2019.

HILL, B. M. Powering Intellectual Property Sharing: How to Make Tesla's Patent Pledge Effective. Journal of Intellectual Property Law, [S.I.], v. 24, n. 1, 2016. Disponível em: https:// digitalcommons.law.uga.edu/jipl/vol24/iss1/10. Acesso em: 15 ago. 2019.

LEWIS, J. I. D. What is "frand" all about? The licensing of patents essential to an accepted standard. In: Cardozo law, 2014. Disponível em: https://cardozo.yu.edu/what\%E2\%80\%9Cfrand\%E2\%80\%9D-all-about-licensing-patents-essential-accepted-standard. Acesso em: 12 ago. 2019.

MORRIS, D. A Closer Look at Tesla's Open-Source Patent Pledge. In: Duane Morris Green IP blog. 2018. Disponível em: https://blogs.duanemorris.com/greenip/2018/12/04/a-closer-look-at-teslasopen-source-patent-pledge. Acesso em: 7 ago. 2019.

OECD/EUROSTAT. Oslo Manual 2018: Guidelines for Collecting, Reporting and Using Data on Innovation, 4th Edition, The Measurement of Scientific, Technological and Innovation Activities. Luxembourg: OECD Publishing. 2018. Disponível em: https://doi.org/10.1787/9789264304604-en. Acesso em: 10 ago. 2019.

OROPO. ORoPO - Open Register of Patent Ownership. [201?]. Disponível em: oropo.net. Acesso em: 15 ago. 2019.

TERUYA, D. Y.; LIMA, A. A. de; WINTER, E. Papel da propriedade intelectual no processo inovativo. In: PROENÇA, A. et al. (org.). Gestão da inovação e competitividade no Brasil. Porto Alegre: Bookman. 2015. p. 57-69.

TESLA. All Our Patent Are Belong To You. 2014. Disponível em: https://www.tesla.com/blog/allour-patent-are-belong-you. Acesso em: 31 jul. 2019.

ZIEGLER, N.; GASSMANN, O.; FRIESKE, S. Why do firms give away their patents for free? World Patent Information, [S.l.], v. 37, p. 19-25, jun. 2014. Disponível em: https://www-sciencedirect.ez9. periodicos.capes.gov.br/science/article/pii/S0172219013001592. Acesso em: 31 out. 2019.

\section{Sobre os Autores}

\section{Silvia Beatriz Beger Uchôa}

E-mail:sbuchoa@ctec.ufal.br

Doutora em Química e Biotecnologia, pelo Instituto de Química e Biotecnologia da UniversidadeFederal de Alagoas (UFAL); mestre em Arquitetura e Planejamento, pela Escola de Engenharia de São Carlos da Universidade de São Paulo (USP).

Endereço profissional: Universidade Federal de Alagoas. Av. Lourival de Melo Mota, s/n., Tabuleiro do Martins, Maceió, AL. CEP: 57072-970. 


\section{Bruno Beger Uchôa}

E-mail: brunouch@gmail.com

Especialista em Direito Constitucional, pela Universidade Anhanguera (Uniderp); Bacharel em Direito, pelo Centro Universitário (CESMAC).

Endereço profissional: Av. General Ramiro de Noronha, n. 294, $1^{\circ}$ andar, Bairro Jardim Cuiabá, Cuiabá, MT. CEP: 78043-180. 